\title{
Carbon, soil, and ecological benefits of REDD+ policies in Southwest China
}

\author{
Heli Lu ${ }^{\mathrm{a}, \mathrm{b}}$, Guifang Liu ${ }^{\mathrm{a}, *}$, Zhong Huang ${ }^{\mathrm{a}}$, Quntao Yang ${ }^{\mathrm{a}}$ \\ ${ }^{a}$ Institute of Natural Resources and Environmental Science / Henan Collaborative Innovation Center for \\ Coordinated Developments in Central China Economic Zone, Henan University, Kaifeng 475004, China \\ b Key Research Institute of Yellow River Civilization and Sustainable Development, Henan University, \\ Kaifeng 475004, China
}

*Corresponding author, e-mail: kf_guif@163.com

Received 5 Feb 2015

Accepted 19 Oct 2015

\begin{abstract}
Taking the Xishuangbanna district in Southwest China as the study region, we made a systematic and comprehensive evaluation of the carbon benefits and ecological benefits of the programme for reducing emissions from deforestation and forest degradation (REDD+) while enhancing forest carbon sequestration capacity in developing countries. It was found that carbon emissions in the study region increased and the landscape tended to fragment. Furthermore, the average carbon emissions of areas with severe soil erosion were more than 6 times higher than that of areas with minor erosion. These results indicate that REDD+ not only reduces carbon emissions caused by deforestation and forest degradation, but also provides other ecological benefits, such as mitigating forest fragmentation, preserving biodiversity, and conserving soil and water. From this perspective, REDD+ provides sustainable forest management and ecological benefits.
\end{abstract}

KEYWORDS: land use change, Xishuangbanna district, carbon emissions, soil erosion, forest fragmentation

\section{INTRODUCTION}

Nowadays, the enrichment of atmospheric $\mathrm{CO}_{2}$ resulting from human activities constitute an important cause of climate change ${ }^{1}$. Tropical rain forests play a key role in responding to an enrichment of global $\mathrm{CO}_{2}$ levels ${ }^{2,3}$; this is because vegetation in tropical rain forests contains more carbon than that in temperate forests and boreal forests. The Fifth Assessment Report (AR5) from the International Panel on Climate Change (IPCC) now estimates that emissions from forestry may constitute less than $10 \%$ of total emissions, which is significantly less than their former estimate of $17 \%^{1,4}$ and that of other sources ${ }^{5}$. The Kyoto Protocol, which aims to stabilize greenhouse gas concentrations and reduce global carbon emissions, however, does not address this aspect due to issues of approval and monitoring. Reducing targets for global greenhouse gas emissions therefore will not ultimately be realized until tropical rain forest regions are included in the international emission reduction framework ${ }^{6,7}$. Now, participating countries at the Warsaw World Climate Summit (COP19) agreed that according to the United Nations Framework Convention on Climate Change (UNFCCC), to reduce greenhouse gas emissions caused by deforestation and forest degradation while enhancing forest carbon sequestration capacity in developing countries, positive incentives or compensation measures, i.e., the programme reducing emissions from deforestation and forest degradation (REDD+) would effectively tackle global climate change. In particular in COP19 on 18th November 2013, the High Level Panel event, which was organized by the COP19 Presidency with the cooperation of Finland and the support from the UNFCCC secretariat, made the following major points during the session: (1) the land sector including forests is very important from the climate perspective; (2) the land sector including forests has potential for cost-effective actions; (3) there are a number of policies and measures already in place in countries, including progress made in REDD+; (4) the land sector should be an integral part of the future climate regime that will be possibly applicable to all parties but respecting national circumstances; (5) the importance of a holistic approach was highlighted; resulting in meaningful actions and enhancing the net effect of the land sector including forests in mitigation and adoption; (6) the future approach should stimulate actions in a broad sense, and could include both market and non-market- 
based approaches. On 20th November the UK, US, Norway, and Germany agreed a $\$ 280 \mathrm{~m}$ package of finance that will be managed by the World Bank's BioCarbon fund to promote more sustainable use of land. Finally, on 23rd November a package of seven decisions - termed "The Warsaw Framework" - on the UN-backed scheme aiming to reduce emissions from deforestation and forest degradation (REDD+) completes the Cancun agreements. There has been also progress on establishing an international mechanism to offer vulnerable populations protection against loss and damage caused by extreme weather events, and to integrate different land use emissions in the 2015 Paris agreement.

Deforestation and forest degradation of tropical rain forests seriously damage forest ecosystems, leading to change in vegetation composition, decrease biodiversity, destroy habitats, aggravate soil erosion, destruct land, and contribute to water pollution $^{8}$. According to the REDD+, to stop deforestation and to govern and restore the damaged forests cannot only maintain and increase carbon storage, but also provide a wide range of ecological benefits, and ultimately enable local residents to tackle climate change and extreme weather ${ }^{9}$.

For those reasons, taking the Xishuangbanna District in Southwest China as a study region, this study evaluates the REDD+ carbon sink benefits and ecological benefits, and defines a relationship between them. For the study, information concerning the changes in land use of the study region was extracted from satellite images in combination with the normalized difference vegetation index (NDVI). In addition, the change in the forest carbon storage of the study region was calculated based on the method of the IPCC greenhouse gas inventory. On this basis, it was estimated that the Revised Universal Soil Loss Equation (RUSLE) and Landscape Index that REDD+ will provide ecological benefits including reduction of soil erosion and forest fragmentation. The final part of the report includes a discussion of the REDD+ mechanisms.

\section{MATERIALS AND METHODS}

\section{Study region}

The study region is the Xishuangbanna district, located at the southern margin of Yunnan Province $\left(21^{\circ} 09^{\prime}-22^{\circ} 36^{\prime} \mathrm{N}, 99^{\circ} 58^{\prime}-101^{\circ} 50^{\prime} \mathrm{E}\right)$, with a total area of approximately $19674 \mathrm{~km}^{2}$ (Fig. 1). It is a district with the largest area of tropical rain forests in China, and it has the most types of tropical forest ecosystems. There are 4500 kinds of higher plants, which accounts for about one-seventh of the total number of higher plants in China. The Xishuangbanna district has a western-type tropical monsoon climate. There is distinct alternation between the dry and wet seasons, the annual mean temperature of the whole district is $10.9-22.6^{\circ} \mathrm{C}$, and annual rainfall is $1138.6-2431.5 \mathrm{~mm}$. Its terrain is lower in the south and higher in the north, higher at the east, west, and north sides and lower in the middle part; the highest elevation is $2429 \mathrm{~m}$ while the lowest elevation is only $475 \mathrm{~m}$, and the relative height is about $2000 \mathrm{~m}$, all form a stereoscopic layout with rich vegetation ${ }^{10}$. The geology, climate, and soil in Xishuangbanna are suitable for the growth and reproduction of various types of flora.

During the past thirty years, due to population growth and increased human activities, as the region is rich in climatic resources and suitable in terrain conditions, there has been rapid economic development of tropical forests for crops such as rubber. Thus deforestation has become serious and forest fragmentation has intensified, which has a significant impact on the environment and biodiversity of the region ${ }^{11}$. Along with the tropical forests being deforested to other land uses, vegetation carbon storage in the Xishuangbanna region has declined, and the distribution pattern of carbon storage has been changed from random to aggregated distribution $^{12}$. This will cause enrichment of atmospheric $\mathrm{CO}_{2}$, which in turn leads to global warming and other issues. As carbon storage in forest ecosystems decreases, the forest landscape structure changes significantly: fragmentation trends become evident. Forest fragmentation is demonstrated by decrease of the core forest area, increase in the number of patches, and isolation among patches, which will have severe impacts on the functioning of the forest ecosystem. Over the past thirty years, soil erosion has also become more and more serious, which causes further degradation of the land, leading to siltation in rivers and lakes, and reducing the control capacity of forests and soils to withstand flooding ${ }^{8}$. All of these problems will perturb the stability of the ecosystem components such as climate, hydrology, and vegetation, and pose a huge threat to the whole ecosystem.

\section{Data and processing}

The study interpreted the land use using four sets of remote sensing image data from 1976, 1992, 1999, and 2007. Among which, MSS images for 1976 and TM images for 1992 were from the U.S. Geological survey (www.usgs.gov); ETM/TM im- 


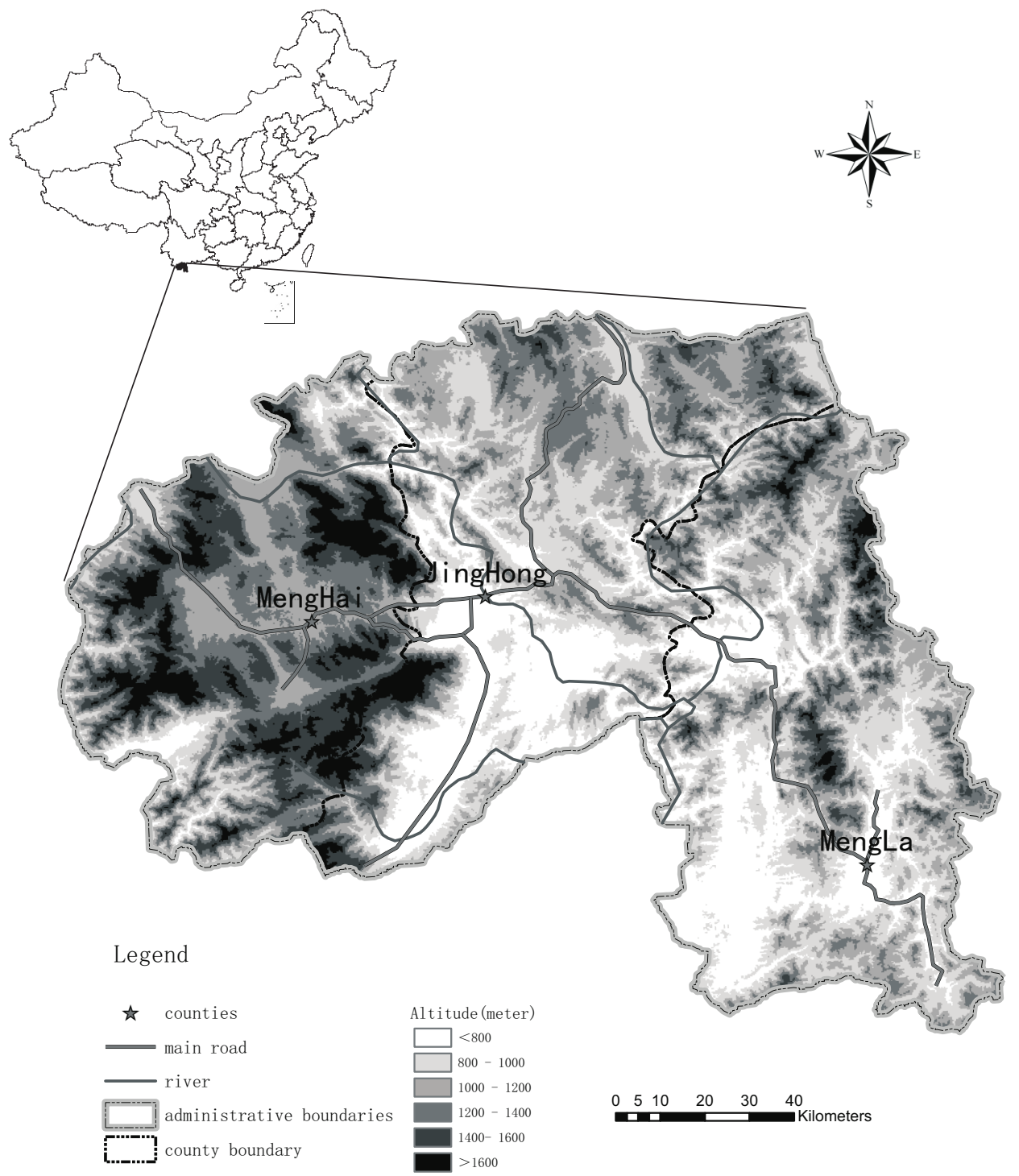

Fig. 1 Map of the Xishuangbanna district.

ages and Terra MODIS images for 1999 and 2007 were from the geospatial data cloud of the Computer Network Information Centre of the Chinese Academy of Sciences (www.gscloud.cn). ETM data recovery for 2007 was made with the stripe recovery model provided by the geospatial data cloud (www. gscloud.cn), with the recovery method of multiimage adaptive local regression. Terra MODIS used the 16-day synthesized L3 data product MOD13Q1.

Through geometric rectification, image registration, and projection transformation, downloaded remote sensing images were transformed to Albers Conical Equal Area projection with a more precise calculation area (central meridian is $105^{\circ} \mathrm{E}$, double standard parallels are $25^{\circ} \mathrm{N}$ and $47^{\circ} \mathrm{N}$, starting latitude is $0^{\circ}$, central meridian deviation and starting point deviation are both 0$)^{13}$. Using the grid analysis tool in ArcMap 10.0 to inset and match image data of the same year, and using the administrative boundary region as a mask, we obtained the image of the Xishuangbanna District.

There were obvious changes of vegetation in the study region from season to season, and the NDVI data for different times have a large impact on the study results. In light of this, the study synthesized the maximum value of multi-date NDVI data for the 


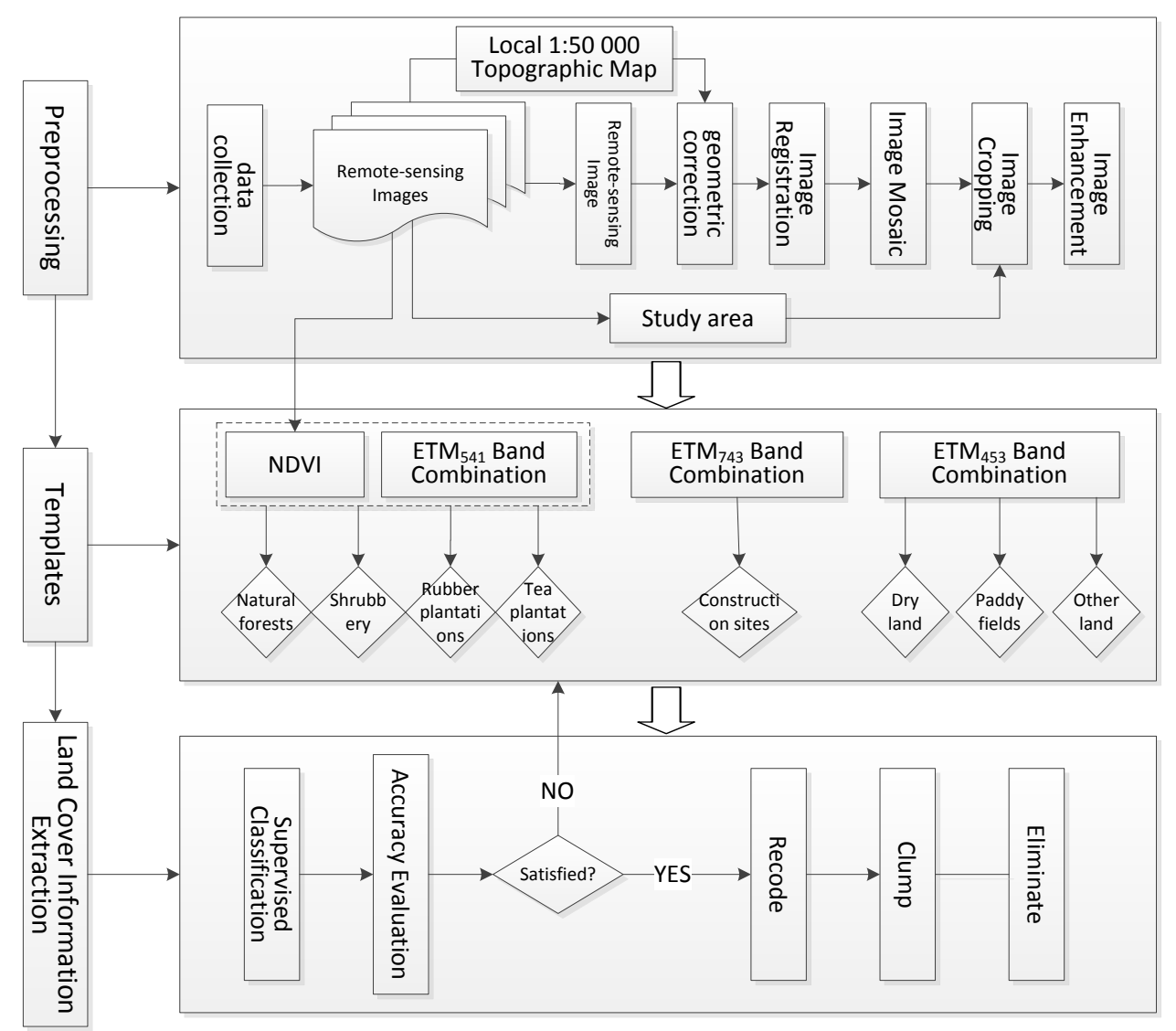

Fig. 2 Land cover information extraction.

same year, which meanwhile eliminates the effect of cloud amount on the study results. As the terrain of the study region is complicated, there were many "similar kinds with different spectra" phenomena during the interpretation of remote sensing images, so it was necessary to select more training samples. Different band combinations of Landsat 7 ETM + $30 \mathrm{~m}$ images are different in characteristics, which provide a base for the selection of training samples. The ETM541 band combination is useful for distinguishing different vegetation types. Supplemented by NDVI data, it can be used for selection of training samples of natural forest, shrubbery, rubber plantations, and tea plantations. The ETM453 band combination can be used for that of dry land and paddy fields; and the ETM743 band combination can be used for the selection of construction sites, and the rest are other lands. The selected training samples were supervised and classified to produce preliminary classification results, and accuracy tests were made. If not qualified, then re-selection of training samples was needed as well as corresponding supervision and classification, and accuracy tests, until satisfactory results were obtained. Finally, the classification results were recoded, clumped, and eliminated, fragmentation patterns were combined into the adjacent largest category, and the smallest unit on the map was unified. The process flow is shown in Fig. 2.

According to the characteristic land use cover of the study region, land use cover in the study was classified into eight classes: natural forest, shrubbery, rubber plantations, tea plantations, dry land, paddy fields, construction sites, and other land. The history of deforestation activities could be traced by making use of the remote satellite images for the years 1976, 1992, 1999, and 2007, with interpretation. According to the definition by the Food and Agricultural Organization (FAO), deforestation is the process of converting forests to other land use classes such as new agricultural land, plantation land, or the long-term process of the decrease in canopy cover area ${ }^{14,15}$. Accordingly, changes observed in natural forest were included in the 'deforestation' category. 


\section{The IPCC method for the calculation of the greenhouse gas inventory}

As part of the national greenhouse gas inventory, the IPCC proposed a series of methods and processes for calculation of the inventory of forestry greenhouse gas in the "IPCC Guide for Land Use, Land Use Change and Good Forestry Practice". To analyse carbon pool change of different land use/cover classes, the IPCC presents two methods that are different but equal in function. First is the method based on carbon storage, i.e., to measure carbon storage at two time points to calculate the change of carbon storage. Second is the method based on process; this method is based on growth curves of trees and ecological models of forests. For this study, the method based on carbon storage, i.e., method 1, was adopted. In this method, carbon storage is calculated by multiplying the area of land use/cover class by the respective carbon density.

According to the IPCC guide, the carbon pool consists of three parts, namely the living biomass (LB) carbon pool, the dead organic matter (DOM) carbon pool, and the soil organic matter (SOM) carbon pool; among which living biomass includes above-ground biomass $(\mathrm{AB})$ and belowground biomass (BB), and dead organic matter includes dead wood (DW) and litter (LT). Total carbon pool storage can be expressed as

$$
C_{\text {Total }}=C_{\mathrm{LB}}+C_{\mathrm{DOM}}+C_{\mathrm{SOM}},
$$

where $C_{\text {Total }}$ is the total carbon pool storage of the land ecosystem, $C_{\mathrm{LB}}$ is the carbon storage of living biomass, $C_{\mathrm{DOM}}$ is the carbon storage of dead organic matter, and $C_{\mathrm{SOM}}$ is the carbon storage of soil organic matter, with the unit t $\mathrm{C}$ (tons of carbon);

$$
C_{\mathrm{DOM}}=C_{\mathrm{DW}}+C_{\mathrm{LT}}
$$

where $C_{\mathrm{DW}}$ is the carbon storage of dead wood and $C_{\mathrm{LT}}$ is the carbon storage of litter.

An assessment of the carbon effect of land use change is made by calculating the annual changes in the pool of living biomass carbon,

$$
\Delta C_{\text {Total }}=\Delta C_{\mathrm{LB}}+\Delta C_{\mathrm{DOM}}+\Delta C_{\mathrm{SOM}},
$$

where $\Delta C_{\text {Total }}$ is the inter-annual variation of total carbon pool storage of the land ecosystem, $\Delta C_{\mathrm{LB}}$ is the inter-annual variation of living biomass carbon storage, $\Delta C_{\mathrm{DOM}}$ is the inter-annual variation of dead organic matter carbon storage, and $\Delta C_{\mathrm{SOM}}$ is the inter-annual variation of soil organic matter carbon storage, with the unit $\mathrm{tC} / \mathrm{y}$ (tons of carbon per year). The inter-annual variation of dead organic matter carbon storage is equal to the sum of that of dead wood carbon storage and that of litter carbon storage,

$$
\Delta C_{\mathrm{DOM}}=\Delta C_{\mathrm{DW}}+\Delta C_{\mathrm{LT}} .
$$

It is necessary for the IPCC method to find a balance between costs and accuracy of calculation results. For this, the IPCC has identified standards for three levels in aspects of calculation methods, parameters, and data sources. For the REDD+ mechanism, it is quite necessary that a certain level of uncertainty be allowed in the calculation results to reduce costs. Chinese scholars have made much effort on the carbon cycles of terrestrial ecosystems and have carried out extensive research on carbon storage and carbon density of vegetation and soil in the Xishuangbanna district, and have achieved fruitful results ${ }^{12,21}$. Zhang et al ${ }^{12,16}$ have written studies on the carbon storage of terrestrial vegetation in the Xishuangbanna district. $\mathrm{Li}$ et $\mathrm{al}^{17}$ have written a study on the soil carbon storage and carbon density in the region. Xiao ${ }^{18}$ and Pang ${ }^{19}$ have, respectively, written studies on vegetation and soil carbon density of tea plantations and rubber plantations in the Xishuangbanna district; all their studies are important references for localization of IPCC carbon emission parameters and are the basis for the calculation of REDD+ carbon sink benefits. Biomass carbon density in natural forest was derived from forest volume inventories which were conducted in 1993-1994 by a broad range of sampling forest within Xishuangbanna district. Based on the growing stock volume, carbon density was calculated using the volume-biomass equations ${ }^{21}$. Carbon densities of shrubbery, tea plantations, rubber plantations, paddy fields, and dry land were taken from the literature (Table 1). The soil carbon densities in difference land use classes were estimated by making use of about one hundred profiles from the second national soil survey in Xishuangbanna district $^{20}$.

Table 1 Parameters used in the calculation of carbon emissions ( $\mathrm{t} \mathrm{C} / \mathrm{hm}^{2}$ ).

\begin{tabular}{lcccc}
\hline Land use classes & Soil & Living biomass & Total & Ref. \\
\hline Natural forest & 99.6 & 45.3 & 144.9 & 16,17 \\
Shrubbery & 109.2 & 9.5 & 118.7 & 16,17 \\
Tea plants & 20.7 & 12.2 & 32.9 & 18 \\
Rubber Plants & 104.7 & 33.4 & 138.1 & 19 \\
Paddy fields & 103 & 0 & 103 & 19 \\
Dry land & 61.9 & 0 & 61.9 & 20 \\
\hline
\end{tabular}


Table 2 Landscape index selection.

\begin{tabular}{lll}
\hline Level & Index & Description \\
\hline Class & NP & Number of patches \\
& AREA_MN & $\begin{array}{l}\text { Mean patch area index } \\
\text { Mean Euclidean nearest } \\
\text { neighbour index } \\
\end{array}$ \\
& SHA_MN & Mean shape index \\
Landscape & NP & Number of patches \\
& AREA_MN & Mean patch area index \\
& COHESION & $\begin{array}{l}\text { Patch cohesion index } \\
\text { Shannon's evenness index }\end{array}$ \\
& SHEI & Shannon's diversity index \\
\hline
\end{tabular}

\section{Measurement of forest fragmentation}

Deforestation has intensified forest fragmentation, and has made significant impacts on the ecological environment and biodiversity in the region, which are a concern regarding REDD+. The study used landscape indices to measure the degree of forest fragmentation in the study region. A landscape index is typically used to measure the composition (quantity, occurrence frequency of a certain composition of proportions, and diversity of landscape elements) and configuration (distribution and spatial location of landscape elements) of the spatial structure of land cover $^{22}$. A landscape index is classified into three levels, patch-level, class-level, and landscape-level, and a total of 9 indicators of the natural forest and shrubbery landscape indices and aggregated landscape index were selected to describe forest fragmentation (Table 2).

Forest fragmentation indices were calculated using the FRAGSTATS program developed by the School of Natural Resources Conservation of the University of Massachusetts. In addition, the land use data used in the study were obtained from remote sensing interpretation with a time series of 1976, 1992, 1999, and 2007.

\section{Soil erosion estimation based on the RUSLE model}

In addition to carbon emissions reductions, the REDD+ mechanism can also bring about non-carbon sink benefits by enhancing ecosystem service functions. An obvious example that many scholars have found is that the ability of water conservation will be enhanced accordingly with an increase in forest area $^{23}$.

For this study, the Revised Universal Soil Loss Equation (RUSLE) was used to estimate soil erosion. The RUSLE model ${ }^{24}$ has been widely used to estimate soil erosion changes caused by nature and human activities. The model reveals the occurrence and changes in soil erosion processes under the combined actions of climate, soil, topography, and land cover factors, and through infiltration and surface runoff $^{25}$. The RUSLE formula for soil erosion calculation is

$$
A=R \cdot L S \cdot C \cdot K \cdot P \text {. }
$$

$R$, the rainfall erosion factor, reflects soil isolation and removal momentum caused by rainfall, i.e., the potential for soil erosion caused by rainfall. By estimating the effect of rainfall on soil particle isolation and removal from a quantitative point of view, it is an important factor for soil erosion prediction. The original RUSLE model makes use of event-based rainfall data to calculate the rainfall erosion factor, but it is not easy to get the data, therefore, statistical annual, monthly, and daily rainfall data from a weather station are generally used to estimate the rainfall erosion factor. Based on Yang Zisheng's approach, the rainfall erosion factor was estimated for this article based on cumulative rainfall of the rainy season (May to October) ${ }^{26}$.

$L$ and $S$ represent the effects of terrain factors causing erosion, and they were used in the joint survey of SRTM data from the National Aeronautics and Space Administration (NASA) and the National Imagery and Mapping Agency (NIMA). Distance to the ridgeline was used as an approximate value for calculation of the slope length, and values of $L$ and $S$ refer to the approach of Yang Zisheng ${ }^{26}$, which was calculated as

$$
L S=\left(\frac{L}{20 \mathrm{~m}}\right)^{0.24}\left(\frac{S}{5^{\circ}}\right)^{1.32}
$$

$C$ is a very important factor as it reflects the impacts of elements of vegetation cover and vegetation management on soil erosion, while these elements are the most likely to be affected by human activities among all elements ${ }^{25}$. As rich vegetation cover is complicated in stand structure, the rate of soil erosion is lower. Conversely, due to lack of vegetation cover on bare land, water loss and soil erosion are more serious ${ }^{27}$. In the RUSLE equation, the $C$ factor is defined as the ratio of soil loss under specific vegetation and specific vegetation management and standard soil loss, when other conditions are the same $^{28}$. In this study, as the difference in NDVI represents different vegetation coverage, we used the vegetation index NDVI to estimate $C$ values. The Terra satellite was launched on 18th December 


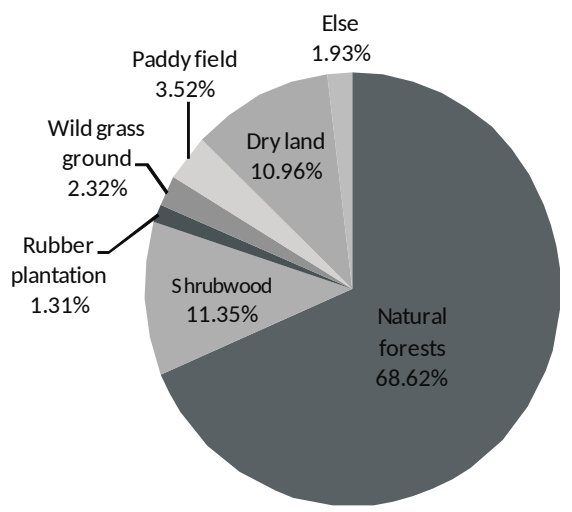

1976

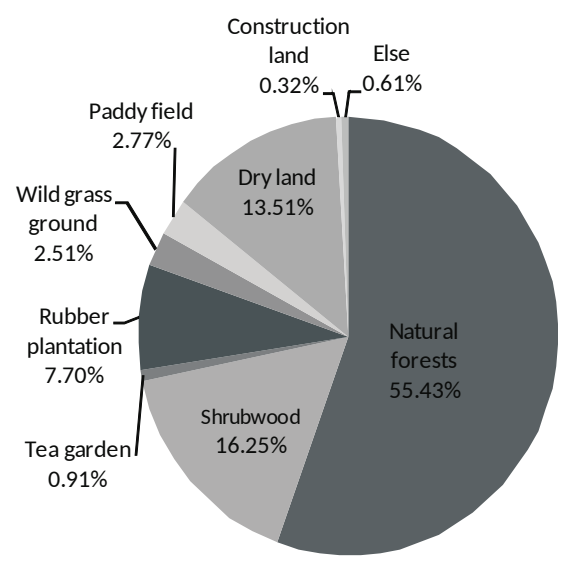

1999

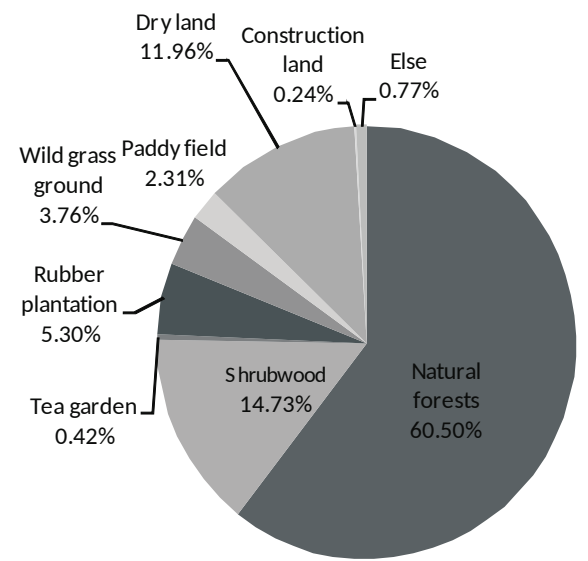

1992

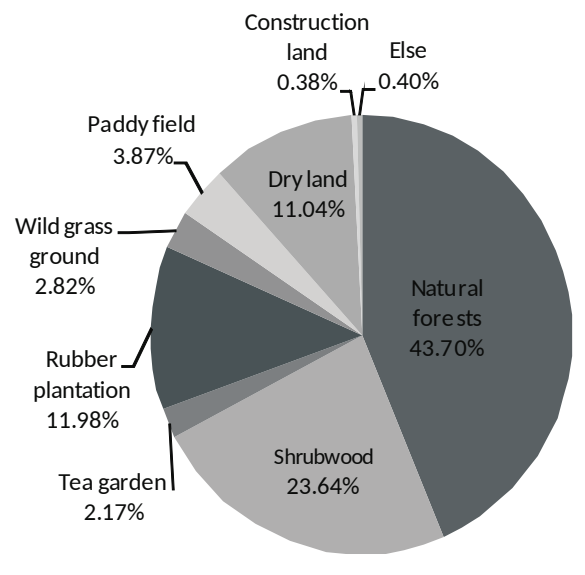

2007

Fig. 3 Land use compositions in (a) 1976, (b) 1992, (c) 1999, and (d) 2007.

1999, so NDVI data before the year 2000 were not available. Thus NDVI data for two periods of 2000 and 2007 were used for the study. Meanwhile, in order to be consistent with land use data, NDVI data for the year 2000 were used in the study as a substitute for NDVI data for 1999.

An approximate $C$ factor can be calculated based on NDVI by using an equation proposed by the European Soil Bureau, $C=\mathrm{e}^{-\alpha(\mathrm{NDVI} /(\beta-\mathrm{NDVI}))}$, where $\alpha$ and $\beta$ are parameters to determine the NDVI $C$-curve shape; usually the value of $\alpha$ is 2 and the value of $\beta$ is $1^{29}$.

$K$ is the soil erodibility factor, which represents the soil loss rate under the units of the rainfall erosion index, depending on soil texture, organic matter content, soil structure and soil permeability. By reference to studies of Yang Zisheng et $\mathrm{al}^{26}$, this article takes its mean value $0.326467 \mathrm{thm}^{2} \mathrm{~h}(\mathrm{MJ}$

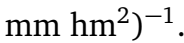

The $P$ factor is the ratio of soil loss after imple- mentation of soil and water conservation measures and soil loss per unit area under down-slope tillage. Due to different management styles, different land use classes will result in different $P$ factors. Soil and water conservation measure factors for the 9 different land classes in the Xishuangbanna district were defined by reference to the study results of Bai Xiaosong ${ }^{30}$. $P$ factor is 1 for natural forest and shrubbery, 0.6 for tea plantations, 0.8 for rubber plantations, 0.01 for paddy fields, 0.55 for dry land, and zero for construction sites and other land.

\section{RESULTS}

\section{Land use change}

Fig. 3 shows land use compositions of the Xishuangbanna district for 1976, 1992, 1999, and 2007 from the interpretation of satellite images. It shows a profound change in land use.

During the 31 years from 1976-2007, the area 
of natural forests declined, while the area of economic forests (rubber plantations and tea plantations) increased at a rapid speed. In 1976, the natural forest cover area of the region was $1.35 \times 10^{6} \mathrm{hm}^{2}$, accounting for $69 \%$ of the total area of the Xishuangbanna district, and it was declining at an average annual rate of $1 \%$ from 1976-2007. By 2007, the natural forest cover area had declined to $8.60 \times 10^{5} \mathrm{hm}^{2}$. In detail, the average annual rate of decline in natural forest area from 1976-1992 was $0.74 \%$, and that from 1992-1999 was $1 \%$, while that from 1999-2007 was $3 \%$, which shows a significant increase in the rate of forest cover loss. However, the area of rubber plantations was increasing at an average annual growth rate of $26 \%$, and it increased from $2.58 \times 10^{4} \mathrm{hm}^{2}$ in 1976 to $2.36 \times 10^{5} \mathrm{hm}^{2}$ in 2007 , with a net area increase of $2.10 \times 10^{5} \mathrm{hm}^{2}$. The area of tea plantations also showed growth at an increasing rate, with an average annual increase from 1976-1992 of $5.20 \times 10^{2} \mathrm{hm}^{2}$, and an increase from 1992-1999 of $1.36 \times 10^{3} \mathrm{hm}^{2}$. The average annual increase in tea plantation area from 19992007 was $3.10 \times 10^{3} \mathrm{hm}^{2}, 5.97$ times that of 1976 1992 and 2.29 times that of 1992-2007. In 1976, the shrubbery area was $2.23 \times 10^{5} \mathrm{hm}^{2}$, accounting for $11 \%$ of the total area of the Xishuangbanna district; while in 2007 , the shrubbery area had increased to $4.65 \times 10^{5} \mathrm{hm}^{2}$, accounting for $24 \%$ of the total area, with an average annual increase of $7.80 \times 10^{3} \mathrm{hm}^{2}$. Paddy fields, and dry land all showed fluctuating changes, but the overall trends were relatively stable.

\section{Carbon emissions caused by land use change}

Calculations of the carbon storage in the Xishuangbanna district in the years from 1976-2007 based on the IPCC method showed a significant reduction in carbon storage in the region during this period. Total carbon storage in 1976 was $2.50 \times 10^{8} \mathrm{t}$, and the amount reduced to $2.491 \times 10^{8} \mathrm{t}$ in 1992 , to $2.478 \times 10^{8} \mathrm{t}$ in 1999 , and even to $2.465 \times 10^{8} \mathrm{t}$ in 2007 , with a decrease of $3.45 \times 10^{6} \mathrm{t}$ in the 31 years. The average annual decrease in the years 1976-1992 was $5.44 \times 10^{4} \mathrm{t} / \mathrm{y}$, and that in the years 1999-2007 was $1.60 \times 10^{5} \mathrm{t} / \mathrm{y}$, indicating a growing trend of carbon emissions in the recent thirty years. In 1976, carbon storage in natural forests was $1.96 \times 10^{8} \mathrm{t}$, accounting for $78 \%$ of total carbon storage, while in 2007 , carbon storage in natural forests was reduced to $1.25 \times 10^{8} \mathrm{t}$, accounting for $51 \%$ of total carbon storage, with average annual carbon emissions of $2.29 \times 10^{6}$ t. Carbon storage

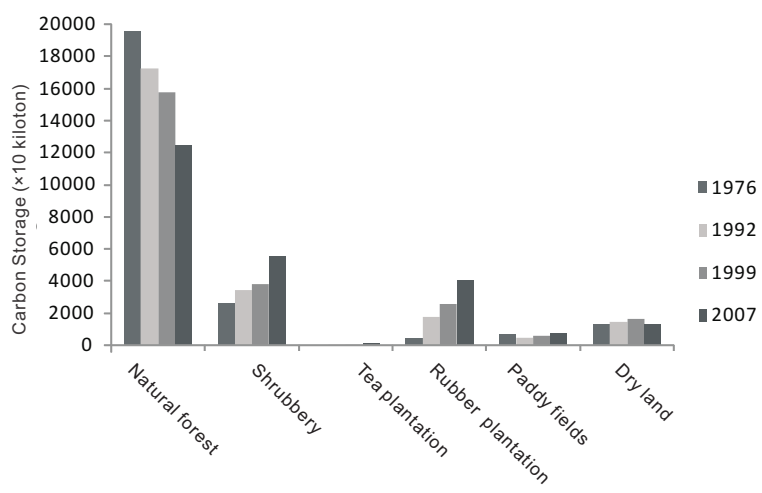

Fig. 4 Carbon storage change by land use class in 1976, 1992, 1999, and 2007.

in natural forests and total carbon storage were both reduced, indicating that the change of carbon storage in natural forests would make a direct impact on total carbon storage. In low elevation areas, large amounts of natural forests were transformed into shrubberies, rubber plantations, and tea plantations. In recent twenty years, deforestation gradually extended from the low elevation, little southern slope area to the high elevation, heavy northern slope area.

Fig. 4 shows a chart of carbon storage change by land use class in 1976, 1992, 1999, and 2007.

\section{Forest fragmentation}

Four periods represented by the years 1976, 1992, 1999, and 2007 were selected for this study to discuss the relationship between carbon emissions and forest fragmentation. The carbon storage of 1992 decreased by $1.7 \%$ compared with that of 1976, that of 1999 decreased by 3.4\%, and that of 2007 decreased by $8 \%$. Accordingly, during the years from 1976-2007, NP increased by $8 \%$, SHDI and SHEI increased by $51 \%$ and $34 \%$, respectively; meanwhile, AREA_MN and COHESION decreased by $26 \%$ and $2.1 \%$, respectively.

\section{Soil erosion}

For this study, soil erosion in the study region was calculated based on the RUSLE model, and the results showed an increasing trend in the total amount of soil erosion in the study region. In 1999, total annual soil erosion in the Xishuangbanna district was $6.44 \times 10^{7} \mathrm{t}$, which increased to $8.24 \times 10^{7} \mathrm{t}$ in 2007, with an average annual growth rate of $3 \%$. The average soil erosion modulus for the whole region was $32.9 \mathrm{t} / \mathrm{hm}^{2}$ in 1999, and it increased to $42.1 \mathrm{t} / \mathrm{hm}^{2}$ in 2007 . Severely eroded areas with 
(a)
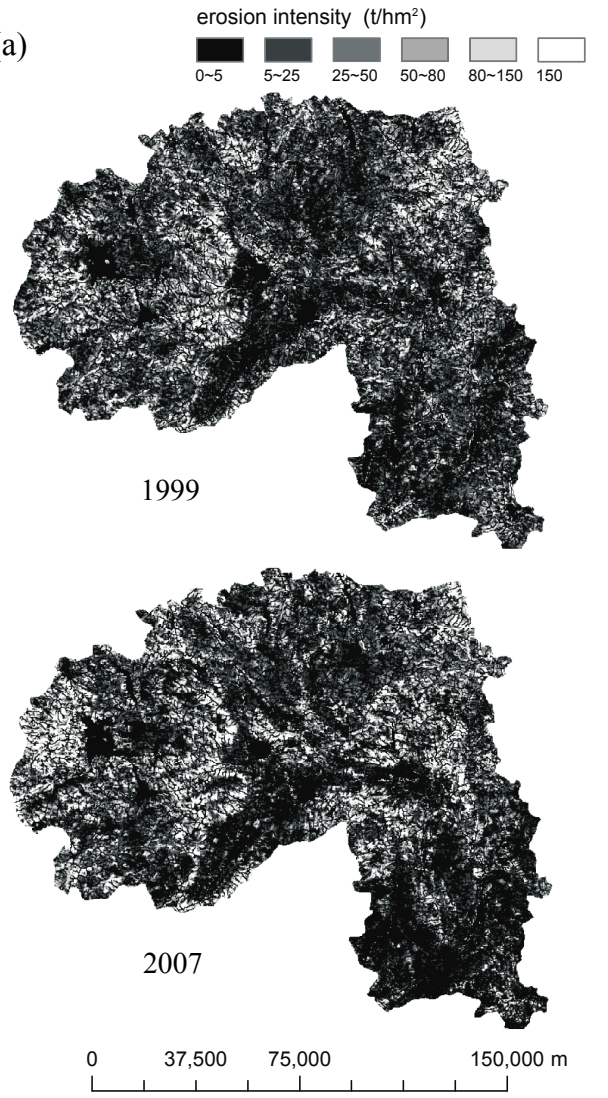

(b)

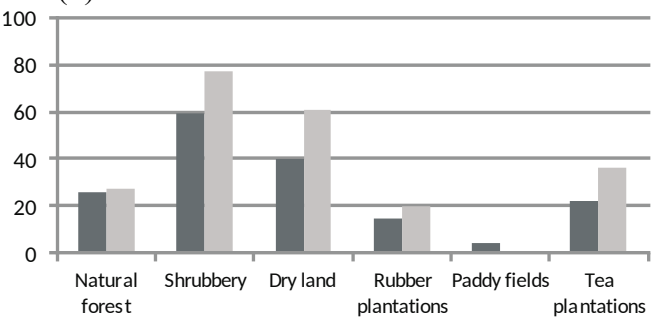

Fig. 5 (a) Soil erosion intensity and (b) soil erosion moduli of different land use types $(\mathrm{t} / \mathrm{ha}$ ) in the Xishuangbanna district.

erosion moduli of over $80 \mathrm{t} / \mathrm{hm}^{2}$ increased from $2.31 \times 10^{5} \mathrm{hm}^{2}$ to $2.78 \times 10^{5} \mathrm{hm}^{2}$, indicating that soil erosion in the region was getting worse.

In order to analyse the effects of different land use classes on soil erosion, statistics on soil erosion moduli of different land use classes have been made available, and the results are shown in Fig. 5. From the figure, the soil erosion moduli of shrubbery is at the maximum, and they contributed more to soil erosion, while the soil erosion modulus of natural forests is smaller. Hence transformation of natural forests into other land classes is the main cause for the increase of soil erosion, while keeping natural forests plays an important role for soil and water conservation.

\section{DISCUSSION}

This evaluation of carbon sink benefits, soil erosion, and ecological benefits in the Xishuangbanna district of China provides an important reference for the REDD+ study. The significance of the study is as follows:

(1) REDD+ is aimed at encouraging carbon sequestration by boosting investments in reforestation and forest protection. Conversion from natural forest to rubber plantation is the most common class of land use change in Xishuangbanna district. In the case of forests clearing, the carbon that was stored in the trees is released and when soils are cultivated, the organic matter in the soil decays and is released to the atmosphere. Although some argued that rubber trees act as a sink for $\mathrm{CO}_{2}$ if they are properly managed so much carbon is lost that the rubber trees need around 20 years to compensate this. Moreover, the carbon sequestrated in rubber trees is mainly converted into litter that is easily decomposable, causing it to return to the atmosphere quickly ${ }^{31}$. Hence mechanism of raising funds from developed countries to assist developing countries to reduce deforestation can contribute to the conservation of carbon storage in Xishuangbanna district.

(2) When forests that would have been lost or degraded are retained or restored through REDD+, they deliver "multiple benefits" in addition to protecting or enhancing carbon stocks. In this case such multiple benefits include conservation of forest biodiversity and soil conservation. Our study reveals that with the carbon storage of 1992 decreasing by $8 \%$ habitat shows the decrease of forest nature degree and the significant increase of fragmentations. Furthermore, since the soil erosion moduli of rubber plantation increases, it contributes more to soil erosion. Although there are fears that, forest carbon 'wins' may equate to 'losses' for biodiversity (win-lose) ${ }^{32}$, conserving tropical natural forest in Xishuangbanna district through REDD+ present opportunities for both reduction of carbon emissions and reduction of forest fragmentation by eliminating or reducing the potential threat of habitat destruction to the entire forest ecosystem (win-win).

(3) A global study of the relationship between biodiversity and carbon sequestration rates did not reveal any significant global correlation ${ }^{33}$. But correlations may exist at the local level. Since the relationship between biodiversity and carbon cycling is increasingly of interest but requires fur- 
ther study, some researchers suggest that regionallevel assessments of biodiversity and carbon stocks should take precedence over global-level studies. Hence, the case-study of forest fragmentation, soil erosion and carbon sequestration in Xishuangbanna district emphasizes the importance of multi-scale decision making in determining environmental priorities.

Acknowledgements: The authors thank the anonymous referee whose comments and suggestions were very helpful in improving the quality of this paper. This project is funded with support from HASTIT (16HASTIT022), 2012CB955800, National Natural Science Foundation of China under project 41371525 titled "Study on Mechanism of Reducing Emissions from China's Tropical Forest Degradation Based on REDD+ Framework", NSFC41430637, 16IRTSTHN012, NSFC41401200, and 15A420003. We also thank Jincai Zhao and Xiaojing Liu for their contribution to this paper.

\section{REFERENCES}

1. Intergovernmental Panel on Climate Change (2007) Climate Change 2007: The Physical Science Basis. Cambridge Univ Press, United Kingdom.

2. Ramankutty N, Gibbs HK, Achard F, DeFries R, Foley JA, Houghton RA (2007) Challenges to estimating carbon emissions from tropical deforestation. Global Change Biol 13, 51-66.

3. Martinuzzi S, Gould WA, Ramos González OM, Martinez Robles A, Calle Maldonado P, Pérez-Buitrago N, Fumero Caban JJ (2008) Mapping tropical dry forest habitats integrating Landsat NDVI and topographic information. Rev Biol Trop 56, 625-39.

4. Intergovernmental Panel on Climate Change (2013) Climate Change 2013: Agriculture, Forestry and Other Land Use (AFOLU), Cambridge Univ Press, United Kingdom.

5. Houghton RA, House JI, Pongratz J, van der Werf GR, DeFries RS, Hansen MC, Le Quéré C, Ramankutty N (2012) Carbon emissions from land use and landcover change. Biogeosciences 9, 5125-42.

6. Lu H, Liu G (2012) A case study of REDD+ challenges in the post-2012 climate regime: the scenarios approach. Nat Resour Forum 36, 192-201.

7. Lu H, Liu G (2013) Distributed land use modeling and sensitivity analysis for REDD+. Land Use Pol 33, 54-60.

8. Li HM, Ma YX, Liu WJ, Liu WJ (2012) Soil changes induced by rubber and tea plantation establishment: comparison with tropical rain forest soil in Xishuangbanna, SW China. Environ Manag 50, 837-48.

9. Yuan M, Xie C, Huang D (2009) A study on development and mechanisms of reducing emissions from deforestation and degradation (REDD). Forest Econ 10, 23-8, [in Chinese].
10. He CG, Feng Y, Yang YP (2008) Research on evolution process and driving factors of forest landscape in Xishuangbanna. Yunnan Geogr Environ Res 20, 12-7, [in Chinese].

11. Cao ZW (2006) Spatiotemporal pattern of land use change along the main road in Xishuangbanna. MSc thesis, Graduate School of Chinese Academy of Sciences, Beijing.

12. Zhang XY, Song WW, Xu ZC, Zhang HJ, Zeng FT (2013) Spatial-temporal evolution characteristic of regional vegetation carbon stock in Xishuangbanna. Ecol Environ Sci 22, 1105-10, [in Chinese].

13. Li ZJ (2008) The land use/cover change and its impact on climate in Xishuangbanna, Southern China. MSc thesis, Graduate School of Chinese Academy of Sciences, Beijing.

14. Food and Agriculture Organization of the United Nations (1993) Forest Resources Assessment 1990: Tropical Countries, FAO, Rome.

15. Food and Agriculture Organization of the United Nations (2001) State of the World's Forests 2001, FAO, Rome.

16. Zhang XY, Xu ZC, Wang JN, Song WW, Qin JQ, Hu XB, Zhang WL, Zou J (2011) Research on forest vegetation carbon stock dynamics and capacity of raising carbon sink in Xishuangbanna. Ecol Environ Sci 20, 397-402, [in Chinese].

17. Li HM, Ma YX, Guo ZF, Liu WJ (2004) Soil organic carbon reserves and space distribution characteristics in Xishuangbanna. In: Annual Conference Proceedings of Chinese Meteorological Society, pp 565-72.

18. Xiao ZW, Wang LJ, Mao JM, Zhu XZ, Wang XL, Zheng L, Tang JW (2012) Carbon storage of different tree-tea agroforestry systems in Xishuangbanna, Yunnan Province of Southwest China. Chin J Ecol 31, 1617-25, [in Chinese].

19. Pang JP (2009) Carbon storage and its allocation of rubber plantation in Xishuangbanna, Southwest China. MSc thesis, Graduate School of Chinese Academy of Sciences, Beijing.

20. Xie XL, Sun B, Zhou HZ, Li ZP (2004) Soil carbon stocks and their influencing factors under native vegetations in China. Acta Pedol Sin 41, 687-99, [in Chinese].

21. Li HM, Ma YX, Guo ZF, Liu WJ, Zhang YP (2005) Carbon storage of forest vegetation and its relationship with affecting factors in Xishuangbanna. J Fujian Coll Forest 25, 368-72, [in Chinese].

22. Giordano F, Marini A (2008) A landscape approach for detecting and assessing changes in an area prone to desertification in Sardinia (Italy). Int $J$ Navig Obs 2008, Article ID 549630.

23. van Dijk AIJM, Keenan RJ (2007) Planted forests and water in perspective. Forest Ecol Manag 251, 1-9.

24. Chen YM, Liu GB, Zheng FL (2004) Proceeding and application on soil erosion model of RUSLE. Res Soil Water Conservat 11(4), 80-3, [in Chinese]. 
25. Renard KG, Foster GR, Weesies GA, McCool DK, Yoder DC (1997) Predicting Soil Erosion By Water: A Guide To Conservation Planning With The Revised Universal Soil Loss Equation (RUSLE), United States Department of Agriculture, Washington DC.

26. Yang ZS (2002) Study on soil loss equation in Jinsha River basin of Yunnan Province. J Mt Sci 20, Suppl., 1-9, [in Chinese].

27. Renard KG, Foster GR, Weesies GA, Porter JP (1991) RUSLE: revised universal soil loss equation. $J$ Soil Water Conservat 46, 30-3.

28. Wischmeier WH, Smith DD (1978) Predicting Rainfall Erosion Losses to Conservation Planning, United States Department of Agriculture, Washington DC.

29. Van der Knijff JM, Jones RJA, Montanarella L (1999) Soil Erosion Risk Assessment in Italy, Joint Research Center of the European Commission, New York.

30. Bai XS (2010) Quantitative study on soil erosion based on RUSLE and ecological suitability evaluation in Northern mountainous areas. MSc thesis, Hebei Agricultural Univ, Baoding, China.

31. Cotter M, Martin K, Sauerborn J (2009) How do "renewable products" impact biodiversity and ecosystem services - the example of natural rubber in China. J Agr Rural Dev Trop Subtrop 110, 9-22.

32. Venter O, Laurance WF, Iwamura T, Wilson KA, Fuller RA, Possingham HP (2009) Harnessing carbon payments to protect biodiversity. Science 326, 1368.

33. Midgley GF, Bond WJ, Kapos V, Ravilious C, Scharlemann JPW, Woodward FI (2010) Terrestrial carbon stocks and biodiversity: key knowledge gaps and some policy implications. Curr Opin Environ Sustain 2, 264-70. 